\title{
VELOCITY-BASED DESIGN OF SEISMIC UNSEATING PREVENTION CABLE AND SHOCK ABSORBER FOR BRIDGES
}

\author{
Shinobu TAKENO ${ }^{1}$, Hiromi OHNO ${ }^{2}$ and Kazuyuki IZUNO 3 \\ ${ }^{1}$ Member of JSCE, Dr. Eng., Engineer, Road \& Transportation Engineering Division, CTI Engineering CO.,Ltd. \\ (4-9-11 Nihonbashi-Honcho, Chuo-ku, Tokyo 103-8430, Japan) \\ E-mail:takeno@ctie.co.jp \\ ${ }^{2}$ Member of JSCE, Ms. Eng., Engineer, Technology Development Group, NEWJEC Inc. \\ (1-20-19 Shimanouchi, Chuo-ku, Osaka 542-0082, Japan) \\ ${ }^{3}$ Member of JSCE, Dr. Eng., Professor, Dept. of Civil Eng., Ritsumeikan University \\ (1-1-1 Noji-Higashi, Kusatsu, Shiga 525-8577, Japan) \\ E-mail:izuno@se.ritsumei.ac.jp
}

\begin{abstract}
The design of connecting devices for preventing bridge girders from becoming unseated during strong seismic motion is extended to include consideration of the velocity response of the bridge. The necessary strength and cross-sectional area of the connecting cable are derived based on conservation of energy considerations, and the shock stress arising when the device becomes active is calculated. The installation of a shock absorber with optimum stiffness based on its deformation limit and the cable stiffness is found to reduce both the impact stress on the cable and the required cross-sectional area. The effectiveness of the proposed design is then verified through numerical simulations.
\end{abstract}

Key Words: bridge unseating prevention system, response velocity, impact stress, shock absorber

\section{INTRODUCTION}

All road bridges in Japan have been fitted with a seismic unseating prevention system to prevent bridge girders from falling during an earthquake. In the current design, the necessary strength of the system is prescribed to be 1.5 times the reaction force for the dead load of the bridge girder. In other words, the capacity is stipulated in terms of the dead load alone, with no consideration of the dynamic response of the bridge system.

With the emergence of the seismic unseating prevention system as an important issue, much research has been conducted in recent years ${ }^{1-9)}$. However, most studies have focused on specific factors in bridge collapse such as cable capacity, while research on the design procedure for the unseating prevention system itself remains limited. The

This paper is translated into English from the Japanese paper, which originally appeared in the Journal of Structural Mechanics and Earthquake Eng., JSCE, No.731/I-63, pp.341-352, 2003. bridge unseating prevention system has been designed based on theoretical considerations under many assumptions because it is difficult to evaluate how the system will operate during an actual earthquake. However, it is necessary to ensure that the system functions adequately during earthquakes.

This research deals with the connecting-cabletype seismic unseating prevention system for elevated highway bridges, presenting a rational design method based on the velocity conditions the connecting device is expected to operate under. The proposed design method involves calculating the necessary sectional area of the connecting cable from the absorbed strain energy for the expected girder velocities, as well as consideration of the impact stress based on stress wave propagation inside the cable. The required stiffness of the shock absorber is then derived in consideration of the abrupt increase in cable force as the shock absorber reaches its deformation limit. In this study, the cable is treated as elastic assuming that the final device should not yield under easily supposed conditions. 


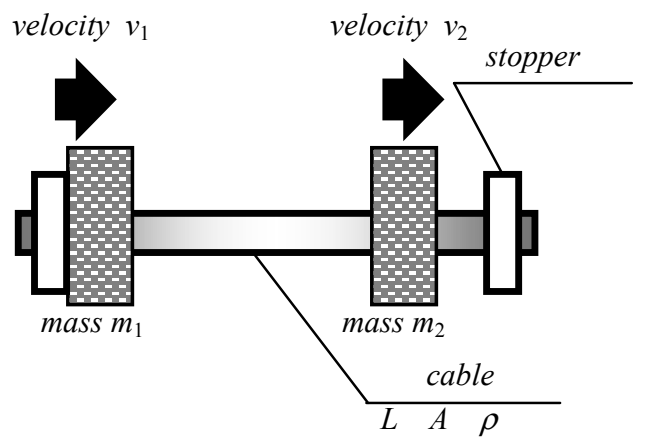

Fig.1 Schematic model of connecting device before operation

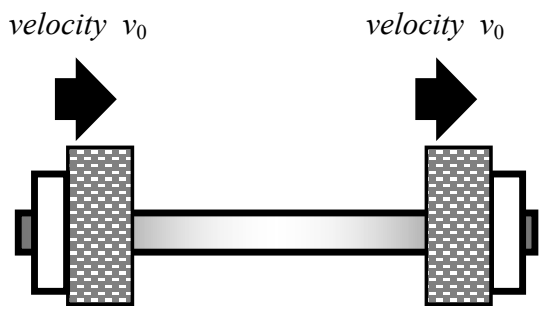

Fig.2 Schematic model of connecting device in operation

\section{NECESSARY CAPACITY OF CON- NECTING DEVICE}

\section{(1) Necessary capacity of cable based on con- servation of energy considerations}

The behavior of the connecting cable during an earthquake is treated here as a simple vibrating problem, and the necessary capacity of the cables is derived based on the law of conservation of energy.

In order to discuss the necessary capacity of the connecting device, it is first necessary to determine the expected movement of girders at which the device will operate. However, it is difficult to predict the response of the device during earthquakes with any degree of reliability. In essence, the connecting device is expected to operate under conditions in which adjacent girders move further than the allowed marginal displacement of the connecting device during a major earthquake. To simplify the problem, it is supposed that no earthquake load acts following the operation of the seismic unseating prevention system.

From the definition of impulse in physics, the load acting on the cable will be proportional to the relative velocity of the adjacent girders. Therefore, it is useful to treat the velocity response of the girders explicitly in this design approach.
Fig.1 shows a general schematic diagram of the model used for analysis. Girders with mass $m_{1}$ and $m_{2}$ are supposed to be moving with speed $v_{1}$ and $v_{2}$ before the operation of the connecting device. A cable with spring constant $k$, density $\rho$ and Young's modulus $E$ is used as a connecting device that connects both girders until the girders reach the same velocity $v_{0}$, as shown in Fig.2. Although there is no guarantee that the girder stops at that time, the connecting cable supports the maximum force when the relative velocity becomes zero.

The following equation can be constructed from the law of conservation of energy, designating cable extension as $\delta$.

$$
\frac{1}{2} m_{1} v_{1}^{2}+\frac{1}{2} m_{2} v_{2}^{2}=\frac{1}{2} k \delta^{2}+\frac{1}{2}\left(m_{1}+m_{2}\right) v_{0}^{2}
$$

From the law of conservation of momentum, the velocity $v_{0}$ just after the connecting cable operates can be derived as follows.

$$
v_{0}=\frac{m_{1} v_{1}+m_{2} v_{2}}{m_{1}+m_{2}}
$$

When $v_{0}$ is eliminated from Eqs. (1) and (2), the maximum cable deformation can be derived as follows, designating the relative velocity of the adjacent girders as $V_{c}=v_{1}-v_{2}$.

$$
\delta=\sqrt{\frac{M}{k}} V_{c}
$$

where $M$ is a reduced mass given by

$$
M=\frac{m_{1} m_{2}}{m_{1}+m_{2}}
$$

The reduced mass allows the description of the motions of the two masses to be reduced to that of an equivalent single mass.

The spring constant of the connecting cable is defined by the following equation in terms of cable length $L$, cross-sectional area $A$, and Young's modulus $E$.

$$
k=\frac{E A}{L}
$$

The maximum deformation of the cable is then derived as follows by substituting Eq. (5) into Eq. (3). 


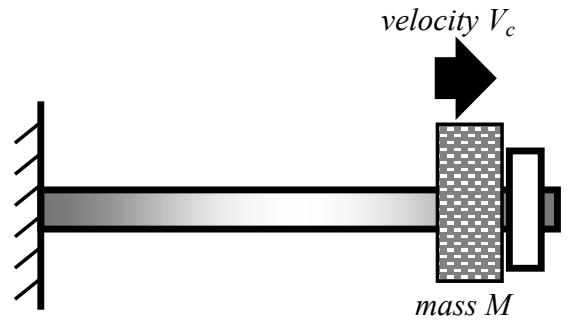

Fig.3 Connecting device modeled with a reduced mass

$$
\delta=\sqrt{\frac{L M}{E A}} V_{c}
$$

Therefore, the maximum stress acting on the cable becomes

$$
\sigma_{E}=E \frac{\delta}{L}=V_{c} \sqrt{\frac{E M}{A L}}
$$

In this paper, this stress is noted as $\sigma_{E}$, indicating that it is calculated based on the law of conservation of energy. To design $\sigma_{E}$ so as not to exceed the yield stress, the cross-sectional area of the cable $\left(A_{E}\right)$ needs to satisfy the following equation.

$$
A_{E} \geq \frac{M E}{L}\left(\frac{V_{c}}{\sigma_{y}}\right)^{2}
$$

\section{(2) Necessary capacity of cable based on impact stress propagation considerations}

When the unseating prevention device operates, high-speed pounding of the girder on the cable stopper may cause impact stress to act on the connecting cable. The impact strength of the cable is derived as follows.

In order to evaluate the impact stress acting on the connecting cable simply, three assumptions are made:

1) The connecting cable is assumed to be an elastic body and the girder is assumed to be a rigid body.

2) The shock wave is assumed to spread in one dimension along the cable.

3) The stress is assumed to act uniformly on the cable section.

One end of the cable is considered to be fixed, and the reduced mass collides with the other cable end with velocity $V_{c}$, as shown in Fig.3. The kinetic energy immediately before impact is given by

$$
\frac{1}{2} k \delta^{2}=\frac{1}{2} \frac{m_{1} m_{2}}{m_{1}+m_{2}}\left(v_{1}-v_{2}\right)^{2}=\frac{1}{2} M V_{c}^{2}
$$

The initial impact stress induced by the pounding of the girder upon the cable stopper can be derived as follows ${ }^{10), 11)}$.

$$
\sigma_{0}=E \epsilon=E \frac{V_{c}}{C_{0}}
$$

where $E$ is the Young's modulus of the cable and $C_{0}$ is the wave propagation velocity.

Since the sum of the impulse and the sum of the momentum derivatives are equal, the impact stress can also be expressed as

$$
\sigma_{0}=\rho \cdot C_{0} \cdot V_{c}
$$

where $\rho$ is the cable density and is characteristic of the cable material. When the connecting cable operates, the initial impact stress $\sigma_{0}$ acting on the end of the cable becomes

$$
\sigma_{0}=\sqrt{\rho E} \cdot V_{c}
$$

This eliminates $C_{0}$ from Eqs. (10) and (11). The impact stress in Eq. (12) acts on the end of the cable, causing a stress wave to propagate along the cable. The cable begins to deform with initial velocity equal to the pounding velocity $V_{c}$, decreasing to zero velocity under the maximum deformation state.

The impact stress propagates at the elastic wave speed $C_{0}$ inside the cable. The equation of motion for an elastic body (density $\rho$ and Young's modulus $E$ ) pounded by a rigid body (reduced mass $M$ ) is given by

$$
M \frac{d v}{d t}+\sigma=0
$$

where $\sigma$ is the impact stress at time $t$. The solution of this differential equation is derived as follows with an initial condition of $t=0$ as Eq. (12).

$$
\sigma=\sqrt{\rho E} \cdot V_{c} \exp \left(-\frac{\sqrt{\rho E}}{M} t\right)
$$

According to Eq. (14), the impact stress at the cable end decreases exponentially with time.

As the impact wave propagates and returns by reflection at the other cable end, the impact stress must be integrated in the time domain. For an impact 


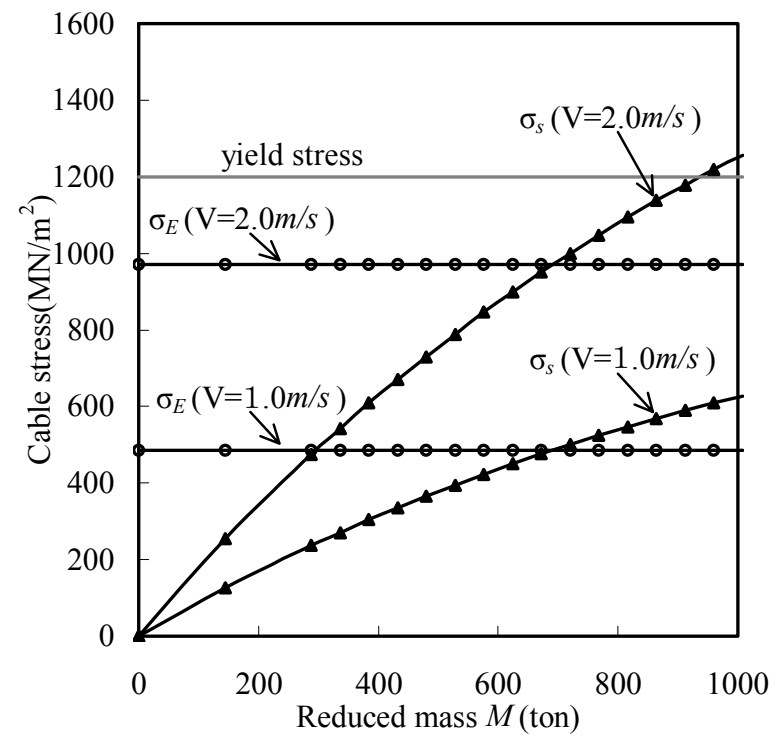

Fig.4 Relationship between cable stress and reduced mass $M$ with design velocity $V_{c}$

wave front progressing through $n$ round trips, the stress of the wave front is described by

$$
\sigma_{n}=\sigma_{n-1}+\sigma_{0} \exp \left(-\frac{\sqrt{\rho E}}{M} t_{n-1}\right)
$$

where $\sigma_{n-1}$ is the stress of the $(n-1)$ th wave front, and $t_{n-1}$ is the impact continuation time from the initial impact to the start of the $(n-1)$ th round trip. The first term on the right-hand side of Eq. (15a) represents the stress when the reflected wave arrives at the initial impact end, and the second term represents the initial stress at time $t_{n-1}$. Substituting $\sigma_{n}$ for the impact stress $\sigma_{s}$ in Eq. (15a) gives

$$
\sigma_{s}=\sigma_{0} \sum_{i=0}^{n-1} \exp \left(-\frac{\sqrt{\rho E}}{M} t_{i}\right)
$$

The relationship between stress $\sigma_{E}$ and impact stress $\sigma_{s}$ can then be examined in terms of the reduced mass. Fig.4 shows a comparison of $\sigma_{E}$ from Eq. (7), derived from the consideration of energy conservation, with $\sigma_{s}$ determined in this section. The length of the cable is set to $3 \mathrm{~m}$, and the cross-sectional area is calculated using Eq. (8) for each reduced mass. The lines in Fig.4 denote design velocities $V_{c}$ of $1 \mathrm{~m} / \mathrm{s}$ and $2 \mathrm{~m} / \mathrm{s}$.

By applying the necessary sectional calculation formula Eq. (8), $\sigma_{E}$ assumes a fixed value irrespective of the reduced mass, whereas $\sigma_{s}$ tends to increase with reduced mass. Below a reduced mass of ap- proximately $700 \mathrm{t}, \sigma_{E}$ tends to exceed $\sigma_{s}$, while the impact stress tends to be larger at smaller masses. Therefore, in the case of $L=3.0 \mathrm{~m}$, if the reduced mass exceeds approximately $700 \mathrm{t}$, it is necessary to examine not only the necessary sectional area calculation formula but also the impact stress formula.

This analysis examined the impact stress in terms of the stress wave propagation in the cable. In the proposed design procedure, the impact stress should be smaller than the yield stress, assuming that the cable is not allowed to yield for a seismic unseating prevention system. The impact stress formula is independent of cross-sectional area, as it was derived assuming a one-dimensional cable. Thus, the necessary cross-sectional area cannot be determined from the impact stress formula. The impact stress $\sigma_{s}$ determined in this way is therefore useful for verification of the section determined from the stress $\sigma_{E}$ given by Eq. (7)

\section{NECESSARY CAPACITY OF SHOCK ABSORBER IN CONNECTING DEVICE}

\section{(1) Modeling of shock absorber}

The authors verified in the previous papers ${ }^{12), 13)}$ that the cross-sectional area of the connecting cable considering the necessary capacity may be much greater than that prescribed in the current design manual. The insertion of a shock absorber is an effective means of reducing the sectional area of the connecting cable by reducing the necessary capacity. A procedure for designing connecting cables with shock absorbers is proposed in this section.

A shock absorber is modeled as a spring element in a similar manner to the cable model in the previous section. The spring constant of the cable is designated $k_{1}$, and that of the shock absorber is designated $k_{2}$. The shock absorber is connected in series with the cable, providing the connecting device with a synthetic spring constant $K$ given by

$$
K=\frac{k_{1} k_{2}}{k_{1}+k_{2}}
$$

Therefore, the deformation $\delta$ of the entire connecting device is expressed as

$$
\delta=V \sqrt{\frac{M}{K}}
$$

The load $P$ that acts on the connecting device is then derived as follows. 


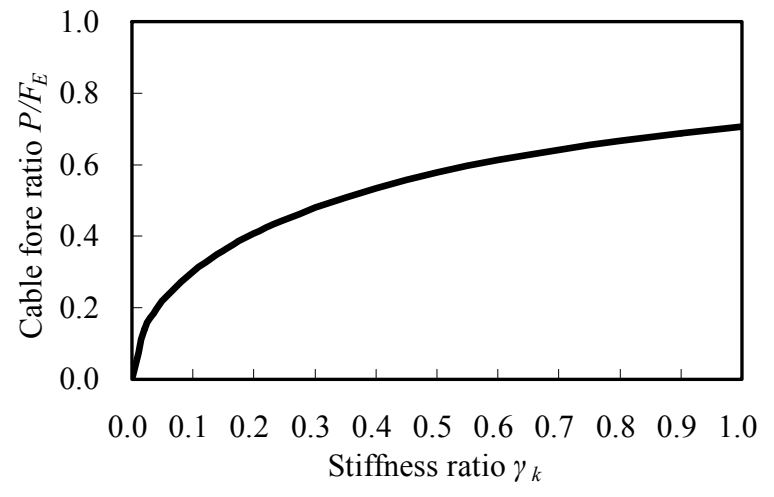

Fig.5 Relationship between relative cable force $P / F_{E}$ and stiffness ratio $r_{k}$

$$
P=K \delta=V \sqrt{M K}
$$

Using $P$ given by Eq. (18), the deformation of the cable $\Delta_{1}$ and that of the shock absorber $\Delta_{2}$ are expressed as

$$
\begin{gathered}
\Delta_{1}=\frac{P}{k_{1}}=\frac{P L}{E A} \\
\Delta_{2}=\frac{P}{k_{2}}
\end{gathered}
$$

\section{(2) Influence of the stiffness ratio between cable and shock absorber}

The ratio of cable stiffness to shock absorber stiffness is defined as $r_{k}=k_{2} / k_{1}$. The stiffness of the shock absorber is then expressed in terms of $r_{k}$ as

$$
k_{2}=r_{k} \frac{E A}{L}
$$

The relative necessary capacity of the cable with a shock absorber compared to the case without a shock absorber then becomes

$$
\frac{P}{F_{E}}=\sqrt{\frac{r_{k}}{1+r_{k}}}
$$

where $F_{E}$ is the necessary capacity of the cable derived from $\sigma_{E}$ given by Eq. (7).

Fig.5 shows the relationship between $r_{k}$ and the necessary capacity of the cable expressed by Eq. (22). The vertical axis represents the relative necessary capacity of the cable with a shock absorber. A very soft buffer is the most effective, with the relative necessary capacity increasing as the stiffness ratio increases (about 0.7 at $r_{k}=1$ ). Therefore, insertion of

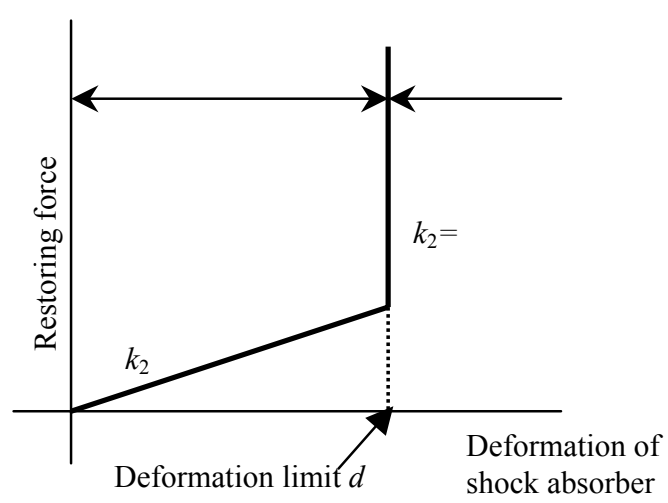

Fig.6 Assumed force-displacement relationship of shock absorber

the softest available shock absorber is effective for reducing the necessary capacity of the cable, regardless of the required size of the shock absorber.

\section{(3) Influence of shock absorber deformation limit}

Equation (22) demonstrated the effectiveness of a soft shock absorber for reducing the necessary capacity of the cable. However, it is expected from Eq. (20) that a soft material will result in large deformation of the shock absorber itself. Therefore, the compression deformation limit of the material used for the shock absorber should be considered. The rubber material commonly used for shock absorbers exhibits a compressional deformation limit due to a limited deformation capacity with nonlinear hardening behavior. Shock absorbers formed from metal springs also exhibit a deformation limit because of the limited compression between coil turns.

Fig.6 shows the force-displacement relationship for an arbitrary linear shock absorber with deformation limit $d$. In the deformation range from zero to $d$ (range (1) in Fig.6), the stiffness of the shock absorber is modeled as $k_{2}$. When the deformation exceeds the deformation limit (range (2) in Fig.6), the stiffness is modeled as infinite.

For cable deformation $\Delta$ when the shock absorber reaches the deformation limit $d$, the following equation can be derived from the conservation of energy.

$$
\frac{1}{2} k_{1} \Delta^{2}+\frac{1}{2} k_{2} d^{2}=\frac{1}{2} M V^{2}
$$

The deformation of the cable $\Delta$ can then be expressed as

$$
\Delta=\sqrt{\frac{1}{k_{1}}\left(M V^{2}-k_{2} d^{2}\right)}
$$




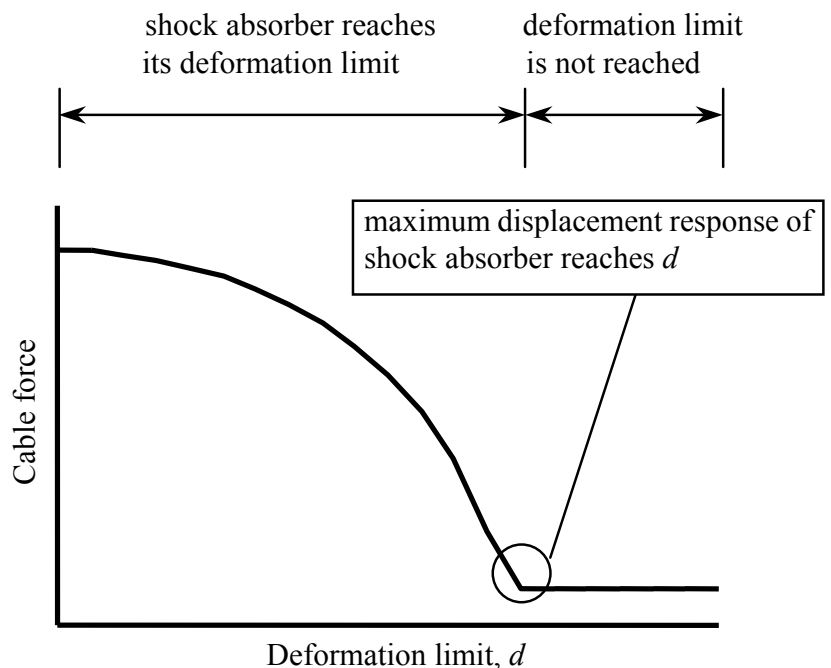

Fig.7 Schematic diagram showing the effect of the deformation limit of a shock absorber

The deformation $\delta$ of the entire connecting device then becomes the sum of the deformation of the shock absorber $d$ and the cable deformation $\Delta$ :

$$
\delta=d+\sqrt{\frac{L}{E A}\left(M V^{2}-k_{2} d^{2}\right)}
$$

The maximum load $P_{d}$ that acts on the connecting device can then be derived as follows from the cable stiffness and the final deformation of the cable.

$$
P_{d}=\frac{E A}{L} \Delta=\sqrt{k_{1}\left(M V^{2}-k_{1} r_{k} d^{2}\right)}
$$

If the shock absorber does not reach the deformation limit $d$, the load $P$ acting on the connecting device is that given by Eq. (18). Equation (26) therefore applies when the calculated deformation is greater than the deformation limit of the shock absorber. Equation (18) indicates that the larger the stiffness ratio $r_{k}$, the larger the load $P$ that acts on the connecting device, whereas Eq. (26) shows that larger $r_{k}$ results in smaller $P$.

\section{(4) Influence of deformation limit on cable re- sponse}

This section discusses the relationship between the stiffness ratio and the deformation limit under conditions of fixed input energy into the connecting device.

First, the relationship between the load applied to the cable (cable force) and the deformation limit of the shock absorber is examined for a fixed value of $r_{k}$. As mentioned above, the variation in cable force differs depending on whether the shock absorber has
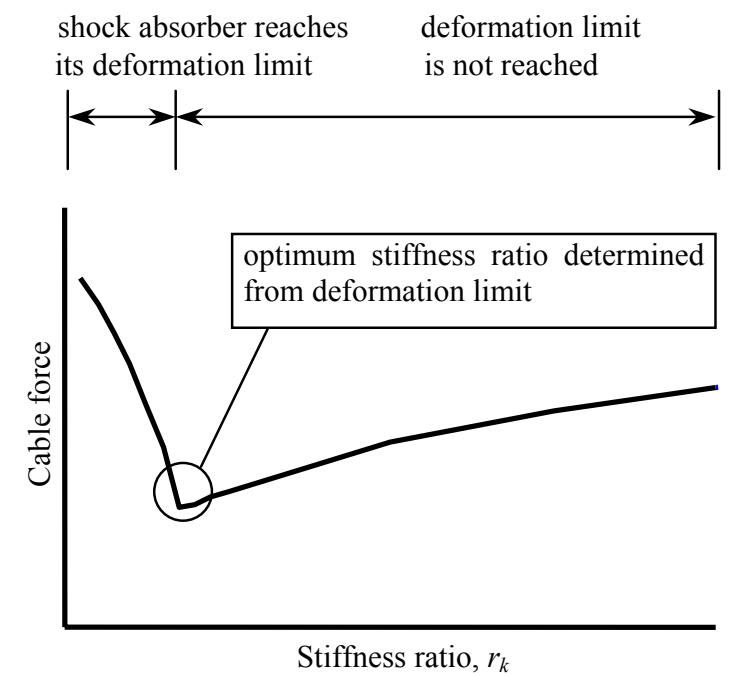

Fig.8 Schematic diagram showing the effect of the stiffness ratio of shock absorber to cable

reached its deformation limit. Fig.7 shows the relationship between cable force and deformation limit. Below the deformation limit of the shock absorber (range (1) in Fig.7), the cable force remains constant. However, when the deformation of the shock absorber reaches its deformation limit (range (2) in Fig.7), the cable force begins to increase. This behavior is exaggerated when the deformation limit is relatively small. Therefore, to ensure that the cable load does not increase undesirably, the shock absorber should operate under the expected conditions within its deformation limit.

Next, the case of fixed deformation limit of the shock absorber is examined. Fig.8 shows the relationship between cable force and stiffness ratio of cable to shock absorber. The variation in cable force is governed by an inequality relation between the response and the deformation limit of the shock absorber. That is, when the response of the shock absorber is within its deformation limit, the cable force increases with the stiffness ratio (range (1) in Fig.8). In contrast, when an external load greater than the design load causes the shock absorber to reach its deformation limit, the cable force increases abruptly with decreasing stiffness ratio (range (2) in Fig.8). The figure also demonstrates that the cable force changes instantaneously when the shock absorber reaches its deformation limit.

An optimum stiffness ratio exists at which the cable force becomes minimum for the given design velocity of the connecting device and the deformation limit of the shock absorber. The optimum stiffness ratio is derived from Eqs. (18) and (26) for condition $P=P_{d}$ as follows. 


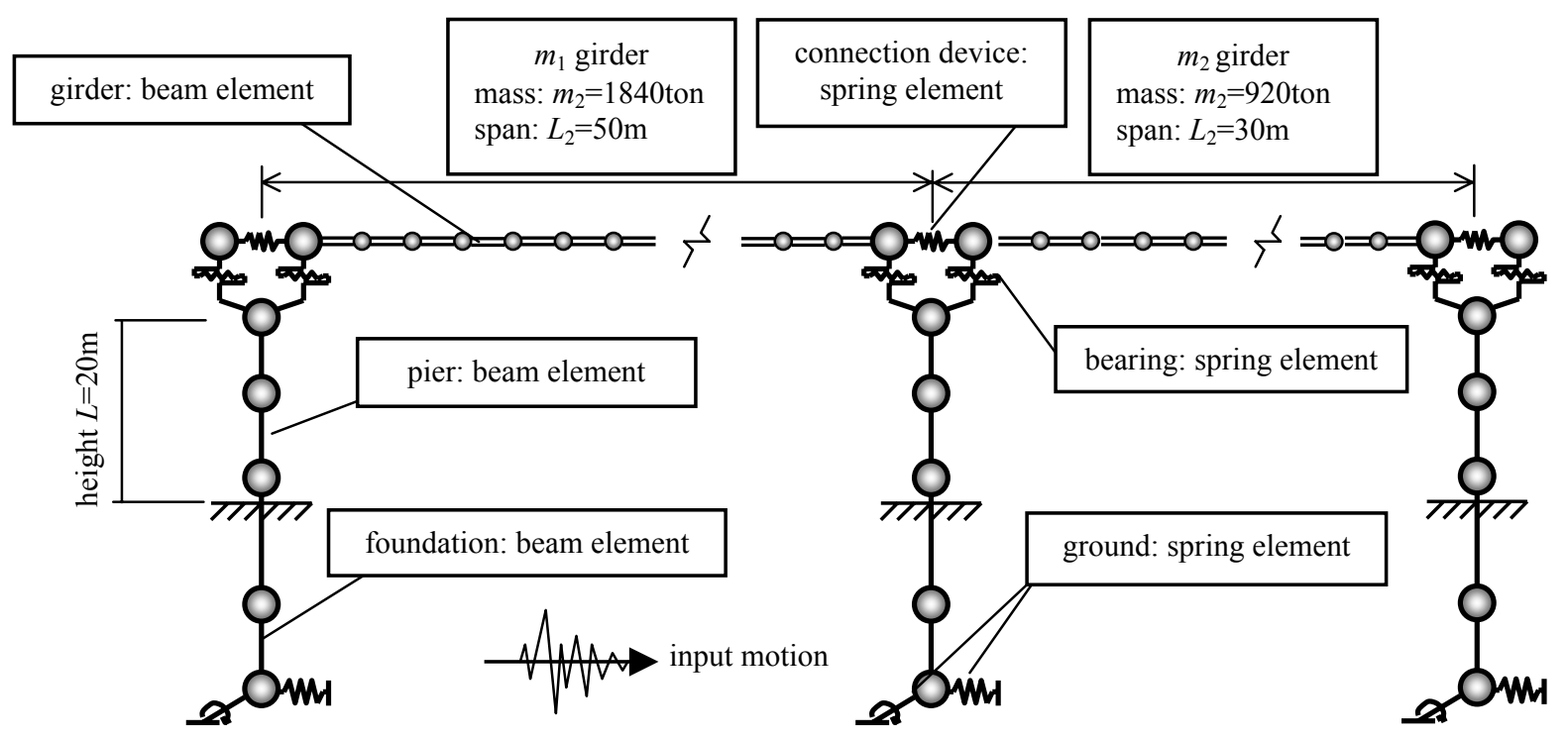

Fig.9 Analytical model for bridge system with connecting device between girders

$$
r_{k}=\frac{1}{2}\left(-1+\sqrt{1+\frac{4 M V^{2}}{k_{1} d^{2}}}\right)
$$

According to Eq. (27), the optimum stiffness ratio decreases as the deformation limit increases, and a higher design velocity for the connecting device requires a stiffer shock absorber.

This analysis reveals that it is necessary to consider the stiffness ratio and the deformation limit in the design of shock absorbers for the connecting device. Although softer shock absorbers are effective under a designated design load, it is important to note that the cable force may increase abruptly when a larger load is applied to the device causing the shock absorber to reach its deformation limit.

\section{EXAMPLE DESIGN OF CONNECTING DEVICE}

\section{(1) Design procedure}

A design example for a connecting device based on the proposed design equations is presented here, and the performance of the device during a large earthquake event is evaluated through numerical simulations. A two-span bridge system is considered, using a two-dimensional nonlinear framework model.

The critical design case for the connecting device is to connect girders with different natural periods. As the Japanese design specification for highway bridges recommends that the natural periods of adjacent connected girders must differ by no more than a factor of 1.5 , the natural period ratio for adjacent girders in this analytical model was set to 1.4.

Bridge spans of $50 \mathrm{~m}$ and $30 \mathrm{~m}$ are considered in this analysis, reflecting typical urban elevated highway bridges. To simplify the problem, the model consists of two simple beams, with the mass of the longer girder denoted by $m_{1}$ and that of the shorter girder denoted by $m_{2}$. The masses were set at $m_{1}=$ $1,840 \mathrm{t}$ and $m_{2}=920 \mathrm{t}$, and the length of the steel connecting cable installed between the girders was set at $L=3.0 \mathrm{~m}$.

The structural model is shown in Fig.9, and the detail of the connecting device is shown in Fig.10. Each member of the bridge system was modeled as a beam element, except for the bearings and the pounding part, which were modeled by nonlinear spring elements.

Although the bridge piers may exhibit a nonlinear response during a huge earthquake, elements with a linear response were used in this model to check the critical state for the connecting device, as no earthquake energy is absorbed when the response of the piers is nonlinear. The actual design will of course require a more detailed model considering the nonlinearity of bridge piers and the ground. The example presented here simply aims to demonstrate the fundamentals of the design procedure considering nonlinearity only at the bearings and the pounding part between girders.

The damping factors were set at 5\% for pier and girder members and $20 \%$ for the foundation and ground. No viscous damping was assumed for bearings or the spring members that express the pounding. Rayleigh damping was assumed based on these val- 


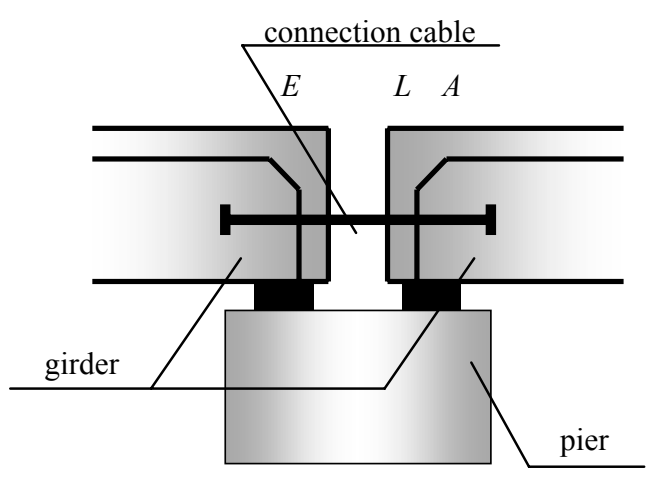

Fig.10 Schematic diagram of connecting device

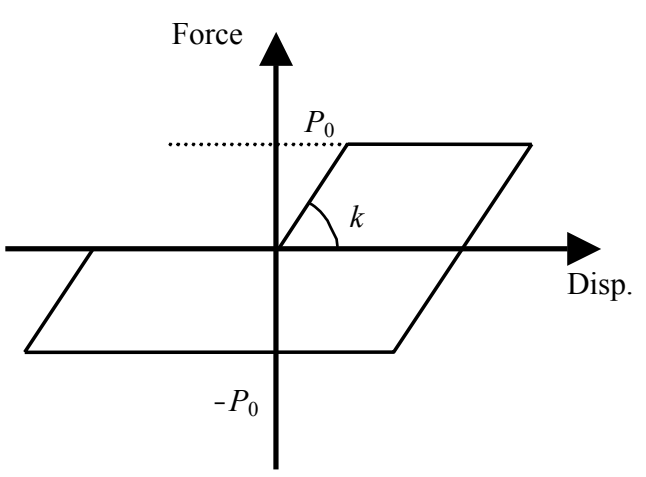

Fig.11 Assumed hysteretic response model of bearing

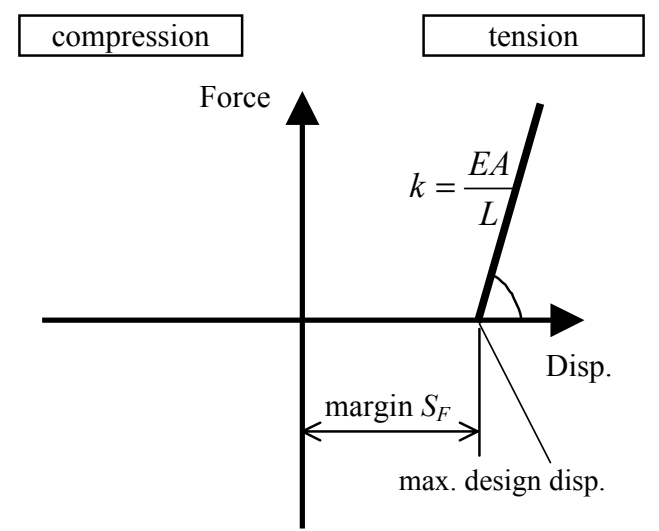

Fig.12 Assumed force-displacement relationship for connecting cable

ues, and the response analyses were conducted by Newmark's $\beta$ method with $\beta=0.25$ and a time increment of $\Delta t=0.001$ using the TDAP-III software package $^{14)}$.

During a huge earthquake, a large relative displacement will cause the girder to fall through de- struction of the bearings. Past experiments regarding the behavior of failed bearings have shown that the force-displacement response of bearings varies widely depending on the specific nature of the seismic event ${ }^{15)}$. In this study, the simplest destructive situation is assumed, in which the girder moves on the pier with friction. The force-displacement relationship for the bearing was thus assumed to follow the bilinear hysteretic model shown in Fig.11. The friction force $P_{0}$ as the product of the reaction force $R_{d}$ for the dead load of the girder and the friction coefficient $\mu$ is assumed to act while sliding:

$$
P_{0}=\mu R_{d}
$$

Although the friction coefficient between the bridge pier and the bearing is not known, a conservative value of $\mu=0.05$ was used in this analysis.

Fig.12 shows the force-displacement relationship for the connecting cable. The marginal displacement of the connecting cable $S_{F}$ is set such that the connecting device only becomes active during design earthquake motion of higher than level 2. The marginal displacement is calculated by the following equation from the bridge seat length $S_{E}$ of the girder and the pier multiplied by the design displacement factor $c_{F}$ according to the Japanese design specification for highway bridges ${ }^{16)}$.

$$
S_{F}=c_{F} \cdot S_{E}
$$

The cable stiffness $k$ is calculated according to the proposed design method or the current design load in each analysis.

A nonlinear spring element was inserted between adjacent girders to express the pounding during an earthquake. Fig.13 shows the force-displacement relationship for the spring element considering pounding. This spring behaves linearly with high stiffness in compression when the response is smaller than the initial distance between girders $S_{B}$. The stiffness for this spring $k_{c}$ is calculated in consideration of the axial stiffness of the girder as follows ${ }^{17)}$.

$$
k_{c}=\gamma \frac{E A}{L}
$$

where $E A$ is the axial stiffness of the girder, $L$ is the length of the girder, and $\gamma$ is the axial stiffness ratio of the spring against the girder ( $\gamma=10$ in this analysis).

The initial distance between girders $S_{B}$ is set according to the Japanese design specification for 


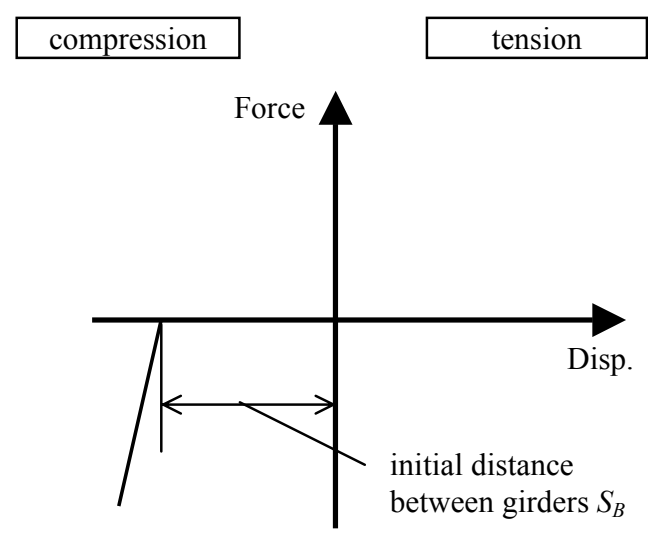

Fig.13 Assumed force-displacement relationship for spring element during pounding

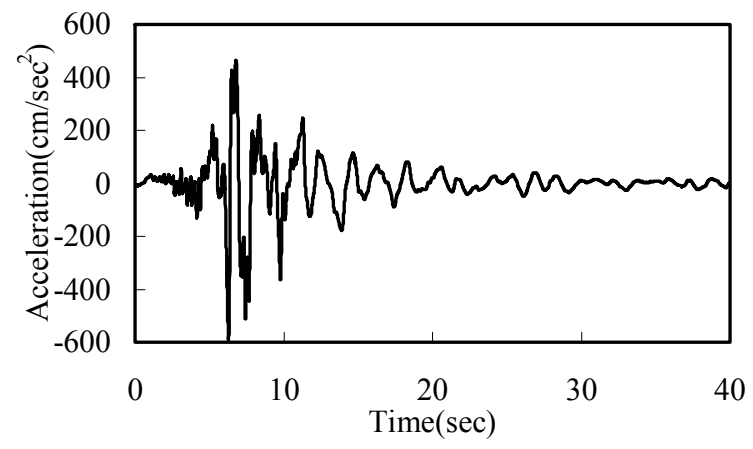

Fig.14 Input earthquake motion

highway bridges as follows.

$$
S_{B}=c_{B} u_{s}+L_{A}
$$

where $c_{B}$ is the correction factor for the distance between the girders considering the natural period of the bridge, $u_{s}$ is the maximum relative displacement response between the girder and the pier for level-2 earthquake motion, and $L_{A}$ is the margin for the initial distance between girders.

The responses of three different devices were compared: the connecting cable prescribed under the current Japanese design specification, and connecting cables designed by the design method proposed in this study with and without a shock absorber. A type-2 waveform for type-III ground was used, as shown in Fig.14, as a standard earthquake input motion for the Japanese design specification for highway bridges ${ }^{16}$.
(2) Connecting device designed by the current Japanese design procedure a) Standard design earthquake motion

The marginal displacement of the connecting cable given by the current Japanese specifications is calculated from the bridge seat length $S_{E}$ of the girder as follows.

$$
\begin{gathered}
S_{E}=0.7+0.005 L_{b}=0.95 \mathrm{~m} \\
S_{F}=c_{F} \cdot S_{E}=0.7 \mathrm{~m}
\end{gathered}
$$

where $L_{b}$ is the girder length, and the design displacement factor $c_{F}$ is set to 0.75 .

The cable stiffness is calculated by the following equations based on the current design procedure ${ }^{18)}$.

$$
\begin{gathered}
A=H_{F} \div\left(\sigma_{y} / 1.7 \times 1.5\right)=128 \mathrm{~cm}^{2} \\
k=\frac{E A}{L}=852 \mathrm{MN} / \mathrm{m}
\end{gathered}
$$

where $H_{F}$ in Eq. (34) is the cable design load under the current design specification.

It is not desirable for the connecting device to become active for standard design earthquake motion because the device is fitted specifically to prevent failure during unexpected strong motion of huge earthquakes. Therefore, a preliminary analysis was conducted to verify that sufficient margins have been provided for the connecting cable.

Fig.15 shows the relative displacement response of adjacent girders in the preliminary analysis. The relative displacement is defined as positive for increased separation. Although the relative displacement response does not reach the marginal displacement during a level-2 earthquake, the negative maximum displacement of the girders reaches the initial distance between girders, indicating that pounding between girders occurred in this simulation.

\section{b) Strong ground motion}

The preliminary analysis above verified that the connecting device does not become active during the standard design earthquake motion. To simulate stronger motion, the standard earthquake waveform with double amplitude was used, although ideally the design should consider the earthquake motion that may occur in the area in which the bridge is constructed.

Fig.16 shows the relative displacement response between the girders in the case of strong motion. The positive maximum relative displacement response exceeds the marginal displacement, indicating that 


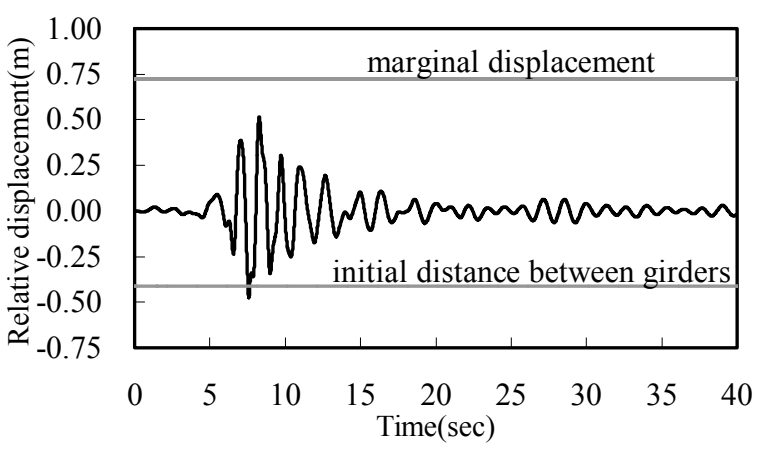

Fig.15 Relative displacement between girders for standard earthquake motion

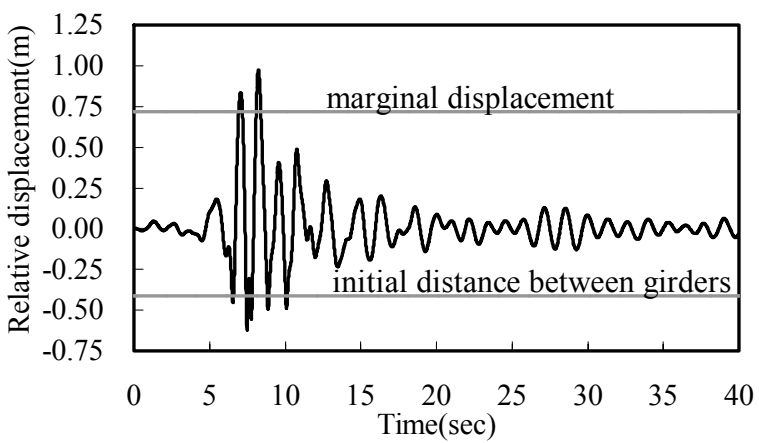

Fig.16 Relative displacement between girders for large input motion

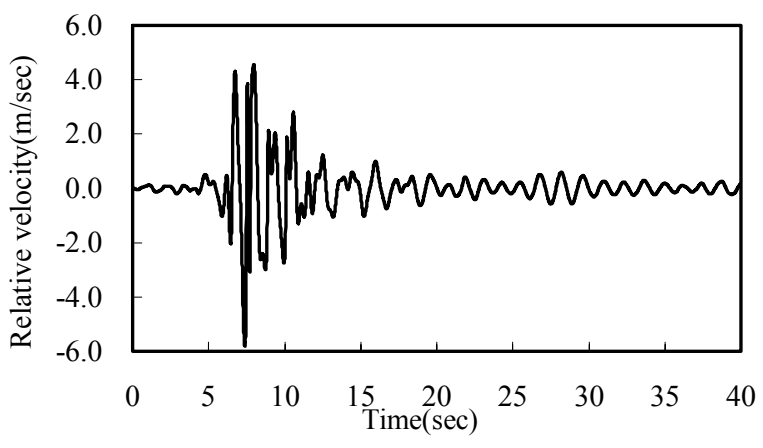

Fig.17 Relative velocity between girders

the connecting device became active during this event. The negative maximum relative displacement also reached the initial distance between girders in this case, and so pounding between girders will have occurred.

Fig.17 shows the relative velocity between the girders over time. The connecting device becomes operational when the maximum velocity reaches about $4 \mathrm{~m} / \mathrm{s}$, and pounding between girders begins at a maximum velocity of about $6 \mathrm{~m} / \mathrm{s}$. As this paper defines the design velocity as the velocity at which the connecting device becomes active, $4 \mathrm{~m} / \mathrm{s}$ is adopted as the design velocity for this case.

Fig.18 shows the hysteretic response of the con-

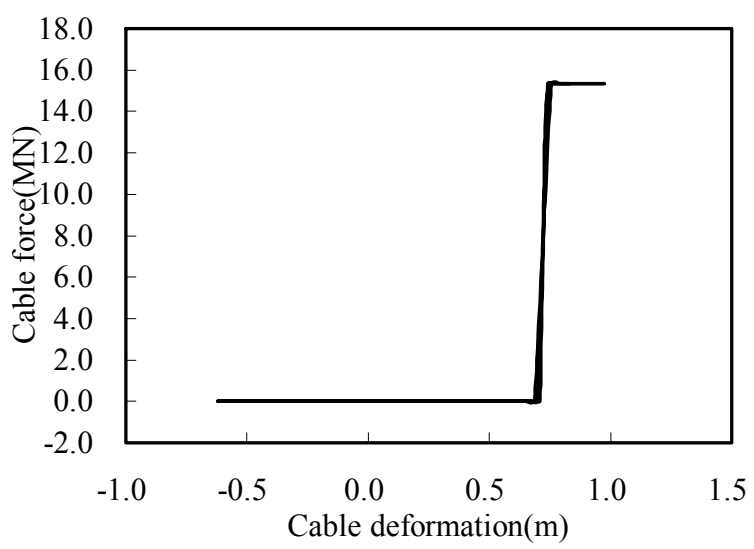

Fig.18 Hysteretic response of connecting cable

necting cable. When the adjacent girders become separated by more than $0.72 \mathrm{~m}$ greater than the marginal displacement of the cable, the cable is pulled in tension to more than its yield displacement of $0.18 \mathrm{~m}$ (corresponding to a yield strain of $6 \%$ for the steel wire). This result indicates the possibility of the connecting cable yielding under the current design procedure when the earthquake motion exceeds the standard design load.

As the current design procedure prescribes the cable section in terms of the dead load alone, the potential for high girder velocity to cause the cable to yield is not considered. This may result in yielding of the cable during large ground motions as in this analysis. In order to ensure that the connecting cable provides adequate protection during large earthquake events, the necessary capacity should be designed considering the dynamic response of the connecting device.

\section{(3) Proposed connecting device}

The performance of the connecting cable designed according to Eq. (8) is examined here using the same marginal displacement $S_{F}$ as considered for the current design. The reduced mass $M$ given by Eq. (4) is calculated as follows.

$$
M=\frac{m_{1} m_{2}}{m_{1}+m_{2}}=613 \text { ton }
$$

The necessary cross-sectional area for the connecting cable is determined assuming a design speed of $4.0 \mathrm{~m} / \mathrm{s}$ derived from the preliminary analysis.

$$
A_{E} \geq \frac{M E}{L}\left(\frac{V_{c}}{\sigma_{y}}\right)^{2}=445 \mathrm{~cm}^{2}
$$




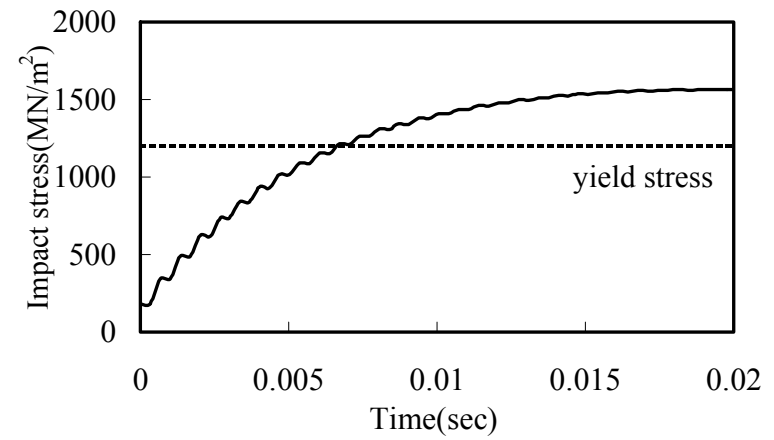

Fig.19 Impact stress response

Considering the cable designed according to the current design procedure has a cross-sectional area of $128 \mathrm{~cm}^{2}$ (Eq. (34)), the proposed design described by Eq. (37) requires a cross-sectional area about three times as large.

Using the equations in section 2, the impact stress for this cable is calculated in order to verify the shock-proof performance of the device. Fig.19 shows the change in impact stress acting on the connecting cable during a strong motion event. The impact stress increases immediately when the connecting device becomes operational, reaching the cable yield stress after $0.015 \mathrm{~s}$ and generating a final stress of 1570 $\mathrm{MN} / \mathrm{m}^{2}$. Therefore, the cross-sectional area of the cable calculated from the energy absorption phenomena is not sufficient to prevent cable failure. Therefore, it is necessary to install an appropriate shock absorber in the connecting device to reduce the impact stress.

\section{(4) Proposed connecting device with shock ab- sorber}

The characteristics of the shock absorber are specified by the deformation limit and the stiffness relative to the cable stiffness. Although the deformation limit would be determined specifically for the product to be installed, a value of $0.15 \mathrm{~m}$ is assumed in this example design. The optimum relative stiffness of the shock absorber is then calculated using the following equation.

$$
r_{k}=\frac{1}{2}\left(-1+\sqrt{1+\frac{4 M V^{2}}{k_{1} d^{2}}}\right)=0.8
$$

Therefore, the stiffness of the entire connecting device, consisting of the cable and shock absorber, then becomes

$$
K=\frac{k_{1} k_{2}}{k_{1}+k_{2}}=1.32 \mathrm{GN} / \mathrm{m}
$$

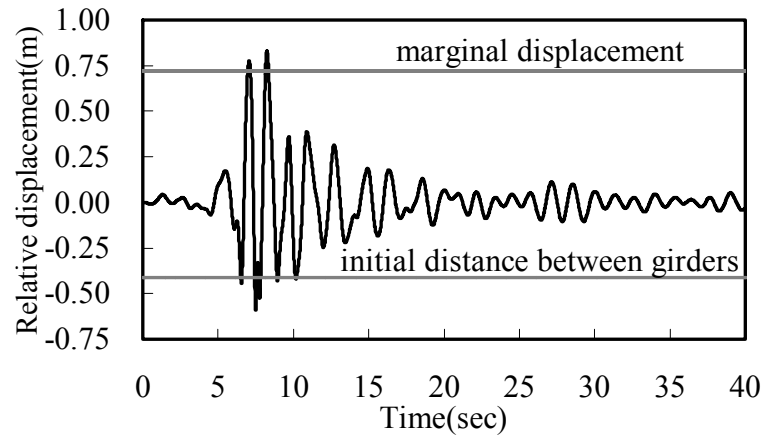

Fig.20 Relative displacement between girders with shock absorber installed

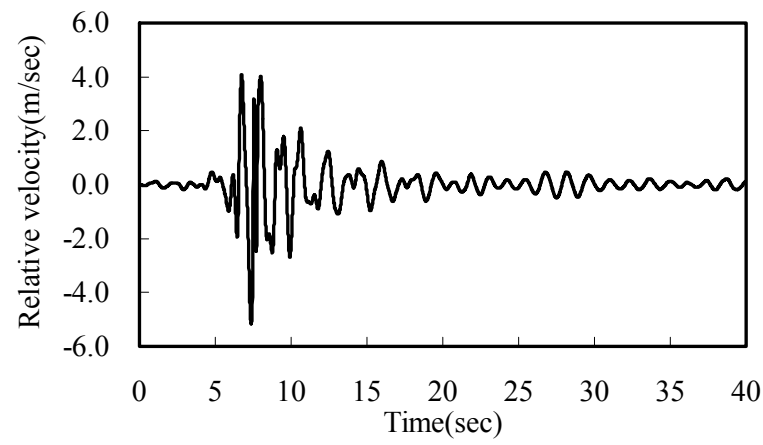

Fig.21 Relative velocity between girders with shock absorber installed

Fig.20 shows the response of the relative displacement between girders during strong motion. The relative displacement between girders exceeds the marginal displacement of the connecting device, indicating that the connecting device has become operational during this simulated event.

Fig.21 shows the response of the relative velocity between girders during seismic motion. The velocity at which the connecting device becomes operational is almost equal to the design speed of $4.0 \mathrm{~m} / \mathrm{s}$.

Fig.22 shows the hysteretic response of the connecting cable. The yield displacement of the device $\delta_{d y}$ is expressed by the following equation in terms of the yield deformation $\delta_{y}$ of the cable and the marginal displacement of the cable $S_{F}=0.72 \mathrm{~m}$.

$$
\delta_{d y}=\delta_{y}+S_{F}=0.90 \mathrm{~m}
$$

From Fig.22, it can be verified that the cable did not yield during this event.

The impact stress acting on the cable with a shock absorber installed is shown in Fig.23. The girder velocity at which the connecting device is operational is expressed as follows considering the installation of the shock absorber. 


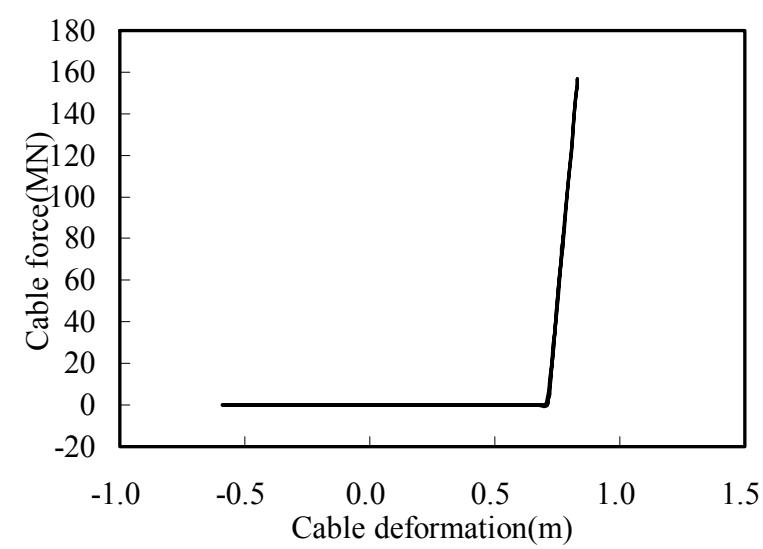

Fig.22 Hysteretic response of connecting cable with shock absorber installed



Fig.23 Impact stress response with shock absorber installed

$$
V=\sqrt{V_{0}^{2}-\frac{r_{k} k_{1} d^{2}}{M}}=2.67 \mathrm{~m} / \mathrm{sec}
$$

The impact stress calculated by Eq. (15b) is 1,040 $\mathrm{MN} / \mathrm{m}^{2}$, which is less than the cable yield stress. This demonstrates that the installation of the shock absorber effectively reduces the impact stress.

Although the unseating prevention system is installed as a measure to prevent girders from becoming unseated from the pier, the device should also be capable of supporting a fallen girder. According to Ref. 9), when a girder falls, the maximum cable force $F_{\max }$ becomes $\alpha$ times the reaction force $R_{d}$ for the dead load of the girder, as follows.

$$
F_{\text {max }}=\alpha R_{d}
$$

The coefficient $\alpha$ is given by

$$
\alpha=1+\sqrt{1+2 \beta}
$$

where $\beta$ is a coefficient expressed as a function of cable stiffness, free-fall displacement of the girder and the reaction force for the dead load of the girder:

$$
\beta=\frac{K \cdot S_{B}}{R_{d}}=0.09
$$

Depending on Eq. (43), $\alpha$ becomes 2.1 for the present simulation model, indicating that the force acting on the connecting device is 2.1 times the reaction force for the dead load. The corresponding stress acting on the cable is calculated as follows.

$$
\alpha R_{d} / A_{E}=282 \mathrm{MN} / \mathrm{m}^{2}
$$

The stress of $282 \mathrm{MN} / \mathrm{m}^{2}$ given by Eq. (45) is significantly less than the cable yield stress of 1,200 $\mathrm{MN} / \mathrm{m}^{2}$, and so the cable has sufficient strength to hold the girder in the event that a girder falls from the pier.

Although the shock absorber was designed here specifically to improve the safety margin, the installation of a shock absorber can also be applied to reduce the required cross-sectional area of the connecting cable. Furthermore, this example simply assumed a design speed of $4.0 \mathrm{~m} / \mathrm{s}$, and a method for setting an appropriate design speed will be an important step for future development of this design methodology.

\section{CONCLUSIONS}

This research extended the factors involved in calculating the necessary capacity of a connecting cable for preventing bridge girders from becoming unseated to include the expected velocity response of the girder during a major earthquake. The necessary cross-sectional area of the cable was calculated based on conservation of energy considerations involving the cable stiffness, girder mass, and girder velocity at which the connecting device is designed to become operational (the design velocity). Then the impact stress was derived based on wave propagation inside the cable, involving the girder velocity and cable material. The stress calculated from energy conservation considerations was found to differ from the impact stress depending on the mass of the connected girders. The installation of a shock absorber was found to reduce both the required cable cross-sectional area and the impact stress acting on the cable. With a shock absorber installed, the cable force remained constant below the deformation limit of the shock absorber but increased abruptly when 
the deformation limit was reached. The optimum stiffness of the shock absorber was then proposed based on the cable stiffness and the deformation limit of the shock absorber.

The proposed calculation scheme is a more rational design method for the specification of connecting devices capable of preventing girders from falling during huge earthquakes. As part of future work, it will be important to: develop a method of setting an appropriate design velocity for the connecting device, define the reduced mass for continuous girder bridges, clarify the energy balance at the time of a connecting cable operation, and investigate the reflectance of stress wave propagation at the ends of the cable. Data for setting the design velocity, for example, could be derived from the maximum recorded pounding velocities for bridges such as the Higashi Kobe bridge during the 1995 Hyogo-ken Nanbu earthquake ${ }^{19), 20}$, or a pounding velocity spectrum ${ }^{21)}$ may be adopted.

ACKNOWLEDGEMENT: This research was supported in part by a Grant-in-Aid for Scientific Research from the Ministry of Education, Science, Sports and Culture of Japan and a research grant from the Kinki Construction Association. The authors thank Mr. Tatsuya Kenzaki and Mr. Hiroshi Kawarabayashi, graduate students of Ritsumeikan University for their help with the numerical simulations.

\section{REFERENCES}

1) Nagashima, F. and Narita, N.: Impact response analysis of the aseismatic tie plates, Journal of Structural Engineering, JSCE, Vol. 40A, pp. 1343-1348, 1994 (in Japanese).

2) Kawashima, K. and Shoji, G.: Effectiveness of rubber type restrainer to mitigate pounding effect between adjacent becks during a strong earthquake: Journal of Structural Mechanics and Earthquake Engineering, JSCE, No. 612/I-46, pp. 129-142, 1999 (in Japanese).

3) Moriyama, T. and Yoda, T.: Experimental study on the effect of pounding between the adjacent girders on the falling girders, Journal of Structural Mechanics and Earthquake Engineering, JSCE, No. 654/I-52, pp. 223-232, 2000 (in Japanese).

4) Ijima, K., Obiya, H., Nishikori, M. and Goto, S.: A study on protection against deck fall of short to middle size of bridge using rubber bearing by permitting impact during an earthquake, Journal of Structural Mechanics and Earthquake Engineering, JSCE, No. 647/I-51, pp.217-228, 2000 (in Japanese).

5) Sonoda, Y., Nishikawa, Y., Ishikawa, N. and Hikosaka, H.: Fundamental study on the mitigating effect of rubber as a shock absorber, Journal of Structural Mechanics and
Earthquake engineering, JSCE, No.689/I-57, pp. 215-224, 2001 (in Japanese).

6) Murata, K., Takayama, T., Goto, T., Yamada, M., Ikoma, N. and Ukishima, T.: Seismic retrofit effect by abridge restrainer with energy absorption, Journal of Structural Mechanics and Earthquake Engineering, JSCE, No. 647/I-57, pp. 274-288, 2001 (in Japanese).

7) Kawashima, K., Uehara, K., Shoji, G. and Hoshi, E.: Shaking table test and analysis of a model bridge for identifying the effect of pounding and restrainers, Journal of Structural Mechanics and Earthquake Engineering, JSCE, No. 703/I-59, pp. 221-236, 2002 (in Japanese).

8) Japan Society of Civil Engineers, Kansai Branch: Report on bridge restrainers with shock absorber installed, 2001 (in Japanese).

9) Izuno, K., Kobayashi, H. and Kamata, K.: Demand capacity for unseating prevention cable to support falling girder, Journal of Structural Mechanics and Earthquake Engineering, JSCE, No. 668/I-54, pp. 319-324, 2001 (in Japanese).

10) The Japan Society of Mechanical Engineers: Shock Destruction Engineering, Gihodo Shuppan Co., 1990 (in Japanese).

11) Taya, T.: Introduction to impulse problems and Laplace transformation, Gakkai Shuppan Center, 1984 (in Japanese).

12) Takeno, S. and Izuno, K.: Demand strength for unseating prevention cables of bridges based on relative velocity response spectra, Proceeding of the JSCE Earthquake Engineering Symposium, Vol. 26, pp. 1165-1168, 2001 (in Japanese).

13) Ohno, H., Takeno, S. and Izuno, K.: Velocity-based design of seismic unseating prevention cable of bridge, Proceedings of the Symposium on Ductility Design Method for Bridges, Vol. 5, pp. 313-318, 2002 (in Japanese).

14) Ark Information Systems: Theoretical Manual of TDAP-III, Ver. 2, 1998 (in Japanese).

15) Usami, T., Abe, M., Fujino, Y., Morishige, Y., Uno, S. and Yanagino, K.: An experimental study about ultimate behavior of bearings under horizontal loading, Proceedings of the JSCE Earthquake Engineering Symposium, Vol. 25, pp. 853-856, 1999 (in Japanese).

16) Japan Road Association: Specifications for Highway Bridges, Part V; Seismic Design (English version), Maruzen, 2003.

17) Watanabe, G. and Kawashima, K.: Analysis of pounding of two elastic rods using impact spring element, Journal of Structural Mechanics and Earthquake Engineering, JSCE, No. 675/I-55, pp. 125-139, 2001 (in Japanese).

18) Japan Road Association: References for Seismic Design of Highway Bridges, pp. 123-139, 1997 (in Japanese).

19) Editorial Committee for the Report on the Great Hanshin-Awaji Earthquake Disaster: Report on the Great Hanshin-Awaji Earthquake Disaster, Part II: Earthquake and Earthquake Ground Motion, pp. 255-258, 1998 (in Japanese).

20) Izuno, K. and Takeno, S.: Research on the collision velocity between adjacent bridges in the earthquake, Proceedings of the Symposium on Ductility Design Method for Bridges, Vol. 3, pp. 209-214, 1999 (in Japanese). 
21) Takeno, S. and Izuno, K.: Estimation of relative velocity response considering pounding between adjacent bridges during earthquake, Journal of Structural Mechanics and Earthquake Engineering, JSCE, No. 668/I-54, pp. 163-175,
2001 (in Japanese).

(Received December 10, 2003) 